\title{
Reflexões sobre a proposta de modificação da regulamentação de rotulagem de alimentos transgênicos no Brasil
}

\author{
Reflections on proposed modifications to the regulation \\ of genetically modified food labeling in Brazil
}

Rayza Dal Molin Cortese (https://orcid.org/0000-0003-3125-8867) ${ }^{1}$ Suellen Secchi Martinelli (https://orcid.org/0000-0001-9263-0867) ${ }^{1}$ Rafaela Karen Fabri (https://orcid.org/0000-0001-5282-9951) ${ }^{1}$ Leonardo Melgarejo (https://orcid.org/0000-0002-3680-7792) ${ }^{1}$ Rubens Onofre Nodari (https://orcid.org/0000-0002-8884-2426) ${ }^{1}$ Suzi Barletto Cavalli (https://orcid.org/0000-0002-2835-9424) ${ }^{1}$
${ }^{1}$ Observatório de Estudos em Alimentação Saudável e Sustentável, Universidade Federal de Santa Catarina (UFSC). R. Roberto Sampaio Gonzaga s/n, Trindade. 88040-900 Florianópolis SC Brasil. rayzacortese@gmail.com

\begin{abstract}
Given the uncertainty surrounding the safety of genetically modified organisms (GMOs), the precautionary principle and constitution provide that consumers should have the right to access adequate information on the presence of transgenics through food labelling. This article discusses the implications of proposed modifications to GM food labelling in Brazil. Current labelling legislation and the government agencies involved in labelling do not guarantee that food products not bearing GMO labels are free of transgenics. The approval of Chamber of Deputies Bill No. 34/2015 goes against the Consumer Protection Code by undermining consumer autonomy and choice. In addition, it is likely to weaken the country's biosurveillance capabilities to identify and seize products that have a harmful effect on the health of humans, animals and the environment. The proposed changes constitute a retrograde step in the regulation of food labelling in Brazil and violate the individual and collective rights enshrined in the Federal Constitution, Consumer Protection Code, and international agreements signed by Brazil.
\end{abstract}

Key words Genetically modified organisms, Food labeling, Biosurveillance
Resumo Diante da existência de incertezas científicas em relação à segurança dos transgênicos para a saúde humana e considerando o Princípio da Precaução e preceitos constitucionais em vigor, o consumidor deve ter o direito de ser informado de maneira adequada sobre a presença de transgênicos nos alimentos, por meio da rotulagem. Este ensaio tem por objetivo apresentar as implicações acerca da nova proposta de rotulagem de transgênicos no Brasil. A atual legislação brasileira de rotulagem de alimentos transgênicos e agências governamentais envolvidas não garantem que os produtos não identificados como tal sejam livres de transgênicos. A aprovação do PLC no 34/2015 contraria dispositivos do Código de Defesa do Consumidor, indo na contramão da escolha $e$ autonomia do consumidor. Além disso, a biovigilância será mais ainda inepta a executar uma atividade de identificação e apreensão de produtos que venham causar danos à saúde humana, animal e ao meio ambiente. A mudança proposta representa um retrocesso na regulamentação de rotulagem de transgênicos vigente no Brasil e um desrespeito aos direitos individuais e coletivos previstos na Constituição Federal, no Código de Defesa do Consumidor e em acordos internacionais assinados pelo Brasil.

Palavras-chave Organismos geneticamente modificados, Rotulagem de alimentos, Biovigilância 


\section{Introdução}

O cultivo de variedades e a comercialização de produtos que contenham ou sejam produzidos a partir de Organismos Geneticamente Modificados (OGM), também conhecidos como transgênicos, podem ser considerados questões centrais para o sistema alimentar diante dos impactos negativos diretos ou indiretos que podem gerar para a saúde, o meio ambiente e a soberania alimentar. Somam-se a isso os interesses políticos e econômicos que estimulam a substituição de culturas alimentícias básicas como feijão, arroz e mandioca por soja e milho transgênicos, sendo a maior parte da produção destinada ao setor agroindustrial, alimentação animal e a biocombustíveis.

Embora não existam estatísticas oficiais, agências mantidas pelo setor agroindustrial informam que o Brasil é o segundo país que mais cultiva plantas transgênicas no mundo, ocupando uma área de 51,3 milhões de hectares, o que equivale a $27 \%$ da produção mundial ${ }^{1}$ e a aproximadamente $70 \%$ da área cultivável brasileira ${ }^{2}$. Do total da área de soja, milho e algodão cultivados no Brasil, 97\%, 88,9\% e 84\%, respectivamente, são variedades transgênicas ${ }^{1}$, o que equivale a virtual totalidade em vista de contaminações biológicas, por fluxo gênico e misturas durante as práticas de colheita, transporte, armazenagem e processamento ${ }^{3}$. Dessa forma, pode-se presumir que a maioria dos produtos e subprodutos derivados de soja, milho e algodão presentes nos alimentos consumidos pela população brasileira provenham de plantas transgênicas, bem como pela população dos países importadores.

Passados 25 anos da liberação da primeira variedade de tomate transgênico, ainda não há um consenso na comunidade científica em relação à segurança do uso e consumo de transgênicos para a saúde humana e animal, bem como para redes tróficas e relações ecológicas fundamentais ao meio ambiente ${ }^{4}$. Contudo, há estudos robustos que indicam efeitos diretos nocivos adversos à saúde humana e animal, tais como alergias alimentares, a toxicidade e a alergenicidade ${ }^{5-8}$, decorrentes do consumo de alimentos produzidos com ou a partir de variedades transgênicas. Além disso, estudos relacionam a expansão de lavouras transgênicas com a ampliação no uso de agrotóxicos ${ }^{9-11}$, demonstrando associações entre a exposição aos agrotóxicos utilizados em culturas transgênicas, como os herbicidas a base de glifosato (HBG), e a maior incidência de doenças crônicas, como câncer, doença de Alzheimer, Parkinson, asma, bronquite, problemas neuroló- gicos, alterações hormonais, infertilidade, desordens gastrointestinais, depressão, transtorno de déficit de atenção, hiperatividade doença cardíaca, autismo, doença celíaca, diabetes e obesida$\mathrm{de}^{12-21}$. Contudo, os estudos aportados pelas empresas dos proponentes da tecnologia concluem que o uso de alimentos transgênicos não causa efeitos adversos à saúde humana e animal e ao meio ambiente.

Diante da controvérsia entre os resultados de estudos independentes e de estudos intramurais, bem como das incertezas científicas de aspectos não estudados, que geram as preocupações em relação à segurança do consumo de transgênicos, principalmente quando se consideram os agrotóxicos associados, é imperativa a implementação de medidas a fim de evitar danos futuros. Nesse sentido, é oportuna e necessária a adoção do Princípio da Precaução, estabelecido tanto na Convenção sobre Diversidade Biológica como no Protocolo de Cartagena sobre Biossegurança, o qual preconiza a tomada de medidas para evitar os riscos potenciais ainda que os danos consequentes, de acordo com o estado atual do conhecimento, não possam ser cientificamente comprovados $^{22-24}$.

Com base no Art. $5^{\circ}$, inciso XIV da Constituição Federal e no Código de Defesa do Consumidor $^{25}$, o direito da população ao acesso a informações sobre os alimentos consumidos está plenamente garantido; assim é essencial que ocorra a identificação de transgênicos em rótulos de alimentos, que por sua vez se constitui na medida adequada para atender também ao Princípio da Precaução. Tal direito deve ser assegurado independente da segurança quanto aos riscos oferecidos pelo produto. A rotulagem é um instrumento com múltiplas funções: (i) permite ao consumidor o direito de ser informado, de maneira adequada, sobre a composição do alimento que está disposto a consumir, o que possibilita escolhas e decisões informadas, (ii) atende a necessidade do consumidor que pertence a um grupo de risco de evitar consumir produtos que não deveria por prescrição médica, e (iii) garante a segurança do consumidor ao permitir o rastreamento e o controle pós-comercialização de produtos alimentícios, possibilitando o controle de qualidade destes produtos ${ }^{26} \mathrm{e}$ pesquisas sobre os impactos na saúde. No entanto, muitos alimentos contendo ingredientes derivados de variedades transgênicas não têm sua composição claramente identificada no rótulo ${ }^{27-30}$.

Considerando o exposto, o objetivo deste ensaio é discutir e apresentar as implicações acerca 
da proposta de rotulagem de alimentos transgênicos nas escolhas do consumidor no Brasil.

A primeira parte deste ensaio busca informar os aspectos regulamentares vigentes, contextualizando as exigências internacionais e o formato de rotulagem adotado pelo Brasil. Na sequência, são apresentadas as modificações regulamentares propostas pelo Projeto de Lei da Câmara - PLC no 34/2015 - e seu impacto na segurança alimentar e escolhas do consumidor.

É importante explicitar que o texto tem como base a experiência dos autores nas áreas de agronomia, genética, economia e nutrição, além da experiência como membros da Comissão Técnica Nacional de Biossegurança (CTNBio).

\section{Aspectos regulamentares vigentes}

O Comitê de Rotulagem de Alimentos do Codex Alimentarius, por meio de grupos de trabalho e reuniões com representantes dos governos de vários países, vem trabalhando desde meados de 1990 no estabelecimento de diretrizes internacionalmente harmonizadas, não vinculantes, para a avaliação e elaboração de recomendações sobre as normas de rotulagem de alimentos transgêni$\cos ^{31,32}$. Na última reunião do grupo, ocorrida em 2003, devido às posições divergentes dos Estados-Membros, não se chegou a um consenso sobre normas de rotulagem destes alimentos. Desse modo, nos últimos anos, muitos países adotaram diferentes orientações internas, o que dificulta sua unificação.

Existem duas abordagens regulatórias para a rotulagem de alimentos transgênicos: (i) a rotulagem voluntária, que não possui força legal para impor a identificação de transgênicos na produção e comercialização de alimentos; e (ii) a rotulagem obrigatória, que exige a declaração do uso da transgenia na produção e comercialização de alimentos $^{31}$. Países como China, Rússia, Indonésia, Brasil e os da União Europeia se basearam no Princípio da Precaução para adotar a rotulagem obrigatória de alimentos transgênicos, diferindo apenas em relação ao percentual de tolerância mínima. Nestes países, onde os alimentos derivados de transgênicos não são considerados substancialmente equivalentes aos convencionais, se reconhece o direito dos consumidores em acessar aquela informação. Já em países como Argentina, Canadá e África do Sul, que se baseiam no conceito da equivalência substancial e defendem a rotulagem voluntária de alimentos transgênicos, isto não acontece ${ }^{33}$. No caso do Brasil, os dossiês elaborados e submetidos pelos proponentes das tecnologias transgênicas à CTNBio contêm informações visando a obtenção da equivalência substancial. Mesmo sem base legal, estes dossiês são aceitos e aprovados.

Outra particularidade que distingue as normas de rotulagem diz respeito ao percentual de tolerância estabelecido para categorização de um alimento como sendo transgênico. Trata-se de opção adotada para compensar situações de contaminação não intencional. Usualmente, estes limites oscilam desde a intolerância absoluta (presença nula, 0\%), passando por aceitação de presença desde que a níveis inferiores a 1\%,3\% ou mesmo $5 \%$ do peso total do produto. Também pode-se aplicar limites em relação à quantidade de cada ingrediente transgênico ou apenas para os três ou cinco ingredientes principais do produto $^{31}$.

Estes diferentes limites da quantidade relativa à rotulagem de alimentos transgênicos podem gerar conflitos nos acordos internacionais de comércio, tanto no que se refere à informação ao consumidor como ao recebimento/aceitação de cargas na importação e exportação de sementes e alimentos ${ }^{31,34}$.

No Brasil, o artigo $6^{\circ}$, inciso III da Lei $n^{\circ}$ 8.078/1990, que instituiu o Código de Defesa do Consumidor, estabelece como direito básico o acesso "a informação adequada e clara sobre os diferentes produtos e serviços, com especificação correta de quantidade, características, composição, qualidade, tributos incidentes e preço, bem como sobre os riscos que apresentem" 25 .

A atual regulamentação da rotulagem de transgênicos no Brasil é normatizada pela Lei de Biossegurança no $11.105 / 2005$, pelo Decreto $n^{\circ} 4.680 / 2003$ e pela Portaria no $2.658 / 2003^{35-37}$. A Lei de Biossegurança, em seu artigo 40 afirma "Os alimentos e ingredientes alimentares destinados ao consumo humano ou animal que contenham ou sejam produzidos a partir de transgênicos ou derivados deverão conter informação em seus rótulos, conforme regulamento" ${ }^{36}$.

No entanto, esta Lei não detalha como seria a rotulagem de alimentos transgênicos. Em 2001, anteriormente à Lei no $11.105 / 2005$, o governo emitiu o Decreto $n^{\circ} 3.871 / 2001$, que estabelecia a obrigatoriedade de rotulagem para alimentos embalados, destinados ao consumo humano, que continham ou eram produzidos com OGM, onde sua presença supera o limite de $4 \%$ do produto $^{38}$. O limite acima referido estabelecia o nível de presença não intencional de transgênicos, percentualmente em peso ou volume, em uma partida de um mesmo produto obtido por téc- 
nicas convencionais. Assim, o limite não era necessariamente sobre o volume total do produto, mas do ingrediente de origem transgênica sobre o total do ingrediente.

O Decreto $n^{\circ} 4.680 / 2003$, por sua vez, determinou a obrigatoriedade da rotulagem para todos os alimentos e ingredientes alimentares destinados ao consumo humano e animal, que contenham ou sejam produzidos a partir de transgênicos, onde sua presença supera o limite de $1 \%$ do produto ${ }^{35}$. Este percentual foi definido com base no nível de presença não intencional considerado tolerável em um produto alimentício devido a eventualidade de contaminação não intencional nas diferentes etapas do processo produtivo. O limite então é definido sobre o volume total do produto e não do ingrediente.

Exemplificando, se um alimento contém 0,4 gramas de soja transgênica e 9,6 gramas de soja não transgênica, o produto seria rotulado pelo Decreto $\mathrm{n}^{\circ} 3.871 / 2001$ independente do volume final ou de outros ingredientes. Todavia, o mesmo produto só seria rotulado pelo Decreto $n^{\circ} 4.680 / 2003$ quando o volume ou peso final do produto fosse inferior a 40 gramas.

Atualmente em vigor, o Decreto $\mathrm{n}^{\circ} 4.680 / 2003$ estabelece que, acima desse percentual de $1 \%$ do produto, tanto os produtos embalados quanto os vendidos a granel ou in natura, informem no rótulo da embalagem ou do recipiente em que estão contidos, em destaque, no painel principal e juntamente com um símbolo, uma das seguintes expressões para informar sua origem e composição/conteúdo transgênico: "(nome do produto) transgênico", "contém (nome do(s) ingrediente(s)) transgênico(s)" ou "produto produzido a partir de (nome do produto) transgênico"35.

Para regulamentar o símbolo previsto no Decreto, foi elaborada pelo Ministério da Justiça a Portaria $n^{\circ} 2.658 / 2003$, que estabelece a identificação visual e gráfica do símbolo. Adotou-se grafia representada pela letra “ $\mathrm{T}$ ” em maiúsculo, no centro de um triângulo amarelo ${ }^{37}$.

\section{Modificações na regulamentação de rotulagem de alimentos transgênicos}

A obrigatoriedade da rotulagem de alimentos transgênicos no Brasil passará por modificações caso o Projeto de Lei no 4.148/2008 (Projeto de Lei da Câmara - PLC no 34/2015) venha a ser aprovado no Senado. O posicionamento favorável da plenária foi obtido em 2015 na Câmara dos Deputados do Congresso Nacional. Na tramitação, as aprovações ocorreram na Comissão de
Agricultura e Reforma Agrária (setembro/2017) e na Comissão de Meio Ambiente (abril/2018), havendo parecer contrário na Comissão de Ciência, Tecnologia, Inovação, Comunicação e Informática (outubro/2015), na Comissão de Assuntos Sociais (março/2018) e na Comissão de Transparência, Governança, Fiscalização e Controle e Defesa do Consumidor (novembro/2019) (Figura 1).

Uma das principais mudanças previstas pelo PLC no 34/2015 é a retirada do símbolo T do rótulo de qualquer alimento transgênico, substituindo-o por expressões como: “(nome do produto) transgênico" ou "contém (nome do ingrediente) transgênico", que já são obrigatórias, segundo o Decreto em vigor. O projeto também propõe alterar a redação do artigo 40 da Lei no 11.105/2005, com revogação do Decreto Presidencial no 4.680/2003 e da Portaria do Ministério da Justiça $n^{\circ} 2.658 / 2003^{39}$, que estabelecem a obrigatoriedade da rotulagem para todos os alimentos e ingredientes alimentares que contenham ou sejam produzidos a partir de transgênicos e a presença do símbolo T.

As expressões mencionadas no parágrafo anterior que devem fazer parte do rótulo, também devem constar no documento fiscal, de modo que, segundo o $\$ 3^{\circ}$ do Art. 2 do Decreto $n^{\circ}$ $4.680 / 2003$, essa informação acompanhe o produto ou ingrediente em todas as etapas da cadeia produtiva. Este dispositivo foi uma inovação visando evitar a necessidade de testes, para facilitar a rotulagem. Com a revogação do Decreto, o país deixará de contar com um sistema barato e eficaz de informação da natureza transgênica do produto transportado, como também de fácil fiscalização.

O PLC no 34/2015 ainda prevê a obrigatoriedade da rotulagem apenas quando a presença de transgênicos for comprovada no produto final por meio de análise laboratorial específica ${ }^{39}$. Esta exigência, em muitos casos, impedirá a comprovação da origem do produto transgênico, uma vez que a detecção só é possível a partir de sequências de DNA inseridas ou de proteínas específicas do transgênico. Assim, alimentos processados ou industrializados contendo algum ingrediente derivado de soja, milho ou algodão transgênico dificilmente serão identificados como tal, pela probabilidade ínfima de identificação de DNA transgênico nestes alimentos. Logo, é altamente provável que alimentos como óleos, bolachas, margarinas e alimentos para crianças na primeira infância não terão a notificação de transgênicos no rótulo, mesmo que elaborados exclusivamen- 


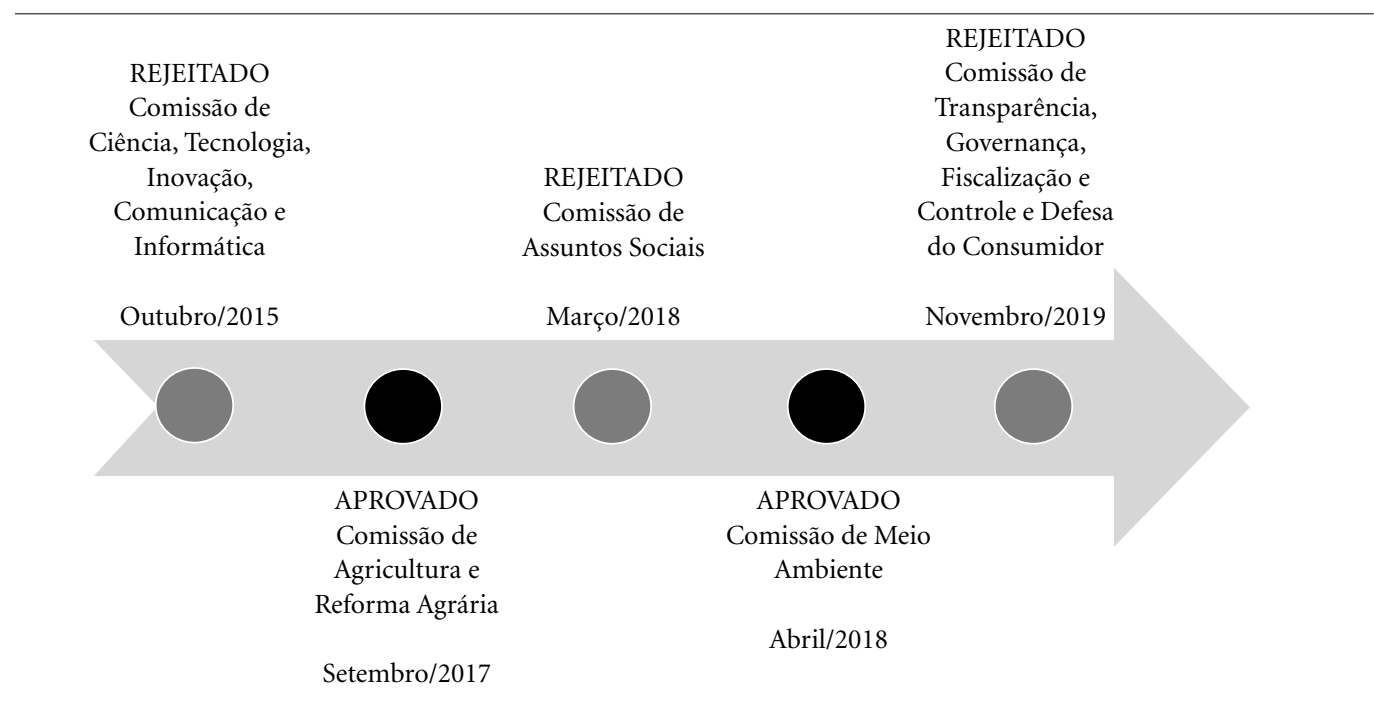

Figura 1. Linha do tempo da tramitação do PLC no 34/2015 nas Comissões, 2019.

Fonte: Elaborado pelos autores.

te com matérias-primas extraídas de lavouras transgênicas. Portanto, devido à dificuldade para identificação de DNA em alimentos com elevado grau de processamento, ainda que estes contenham ingredientes transgênicos, tal informação será negada ao consumidor.

Atualmente a identificação da origem transgênica é realizada baseada na matéria-prima utilizada. Trata-se de identificação confirmada desde o início do processo produtivo. Assim, se determinada cultura transgênica for utilizada na produção de um alimento, a rotulagem do produto final deverá indicar a origem transgênica, mesmo que análises de DNA não permitam sua identificação objetiva. Dessa forma, um óleo derivado de soja transgênica deve ser rotulado como tal, embora no produto consumido não seja possível detectar DNA e proteína transgênica. Considerando a facilidade de se identificar a presença de transgênicos na matéria-prima utilizada no início do processo, bem como seu fácil acompanhamento ao longo da cadeia produtiva, reduzem-se os custos de análise, dispensando o varejo de comprovações laboratoriais.

Além de ampliar os custos e tornar o processo de análise mais complexo, as modificações previstas na legislação podem levar à rotulagem de alimentos como "livres de transgênicos", mesmo quando elaborados com ingredientes derivados de culturas transgênicas. Isso porque o PLC n ${ }^{\circ}$ 34/2015 também prevê a rotulagem "livre de transgênicos" para produtos cuja análise específica não comprove a presença de transgênicos. Com isso, muitos itens contendo ingredientes derivados de transgênicos passarão a ser rotulados como "livre de transgênicos", induzindo a decisões mal informadas, ou mesmo equivocadas, por parte do consumidor. Ademais, esta condição estaria prejudicando agricultores e empresas alimentícias que produzem alimentos sem ingredientes transgênicos.

Estudo de Cortese ${ }^{40}$, obtido a partir de censo realizado em supermercado com rótulos de alimentos, revelou que dos 5.048 produtos analisados, 2.648 (52,5\%) continham algum ingrediente possivelmente transgênico. Contudo, apenas 117 $(4,3 \%)$ daqueles alimentos continham tal informação, apresentando-se rotulados de maneira adequada em respeito ao Princípio da Precaução. Os autores identificaram um total de 28 subprodutos das culturas transgênicas (soja, milho e algodão e uma levedura) cultivadas no país com aplicações para a indústria alimentícia. Estes itens foram encontrados com diferentes nomenclaturas em $64,5 \%$ dos alimentos mais consumidos pela população brasileira sem que os rótulos o indicassem. Destaca-se aqui a obrigatoriedade legal de que, sendo comprovada a presença de material transgênico em níveis superiores a $1 \%$, tal informação deve constar no rótulo do alimento.

Constata-se, dessa forma, que a legislação brasileira de rotulagem de transgênicos se torna- 
rá praticamente inócua, além de enganosa, pois a indicação da ausência de ingredientes transgênicos no produto não pode ser tida como segura, porque não tem base científica. Além disso, nos moldes atualmente em uso, e a despeito da legislação em vigor, não pode ser aceita como válida, pois exigirá que o consumidor domine a nomenclatura e a relação dos componentes possivelmente transgênicos para identificá-los nos rótulos ${ }^{41}$.

Trata-se de condição irreal pela abrangência envolvida. O estudo identificou, em 5.048 alimentos, 101 nomenclaturas distintas para ingredientes possivelmente transgênicos, derivados de milho, soja e algodão (ou ainda referente à presença da levedura transgênica Saccharomyces cerevisiae). Desses ingredientes, 30 eram termos referentes aos derivados de milho, 26 de soja, três de algodão e um referente à levedura. Trinta e dois termos não informavam a origem do ingrediente, podendo ser comum aos três itens, como gordura vegetal e óleo vegetal, que podem ser provenientes de milho, soja, algodão ou algum outro vegetal $^{42}$. Diante disso, destaca-se a dificuldade da população em identificar a presença desses ingredientes possivelmente transgênicos em alimentos, situação que se agravará com a eventual retirada do símbolo previsto na lei em vigor.

Legalmente, no âmbito do estado de Santa Catarina, a rotulagem é obrigatória em produtos alimentícios transgênicos e derivados, independente da quantidade. Além disso, há inclusive vedação de industrialização e comercialização pelo Art. 2 da Lei no 12.128, de 15 de janeiro de 2002, no estado de Santa Catarina, caso não expressem no recipiente, embalagem e rótulo, a informação de que no seu processo produtivo utilizaram-se técnicas transgênicas. Arguido de inconstitucional por indústrias do setor de alimentação, porque não estabelecia um limite para a obrigatoriedade de rotulagem, o Judiciário manteve a legalidade da legislação catarinense que, no entanto, tampouco é cumprida.

Em agosto de 2012, o Tribunal Regional Federal da 1a Região, em Brasília, determinou que as empresas alimentícias deveriam informar aos consumidores sobre a existência de transgênicos na composição dos alimentos, independentemente do percentual ou de qualquer outro condicionante. A ação, proposta pelo Ministério Público Federal e pelo Instituto Brasileiro de Defesa do Consumidor (Idec), visava assegurar informação adequada ao consumidor, para qualquer produto transgênico. Esta orientação não está sendo cumprida até o momento presente ${ }^{43}$.
O decreto em vigor desde 2003 estabelece como obrigatória a presença do símbolo definido pela Portaria no 2.658/2003 e do nome da espécie doadora de genes no rótulo daqueles alimentos produzidos a partir de transgênicos, ou que contenham mais de $1 \%$ de ingrediente transgênico. Já o PLC no 34/2015 considera inapropriada a utilização do símbolo T por estar associado à ideia de risco, perigo, nocividade, cuidado e alerta. Contudo, de acordo com estudo de Hakim et al. ${ }^{44}$, apenas $6 \%$ dos consumidores identificaram o símbolo como uma indicação de algo perigoso, contradizendo os argumentos do projeto de lei. O PCL ainda prevê a exclusão de informação sobre a espécie doadora de genes, na identificação dos ingredientes transgênicos, por considerar se tratar de conteúdo de difícil compreensão pelo consumidor ${ }^{39}$.

No estudo realizado por Cortese ${ }^{40}$, dos 117 alimentos que continham o símbolo $\mathrm{T}$, sete dispunham da informação isolada referente à espécie doadora de genes e 114 (2,8\%) apresentavam de maneira completa as duas informações (o símbolo e o nome da espécie doadora de genes). Apenas estes, menos de 3\% do total, estariam em conformidade com a legislação de rotulagem de alimentos transgênicos. Embora alguns alimentos analisados não contivessem o símbolo $\mathrm{T}$, facilitador da identificação, eventualmente informavam a espécie doadora de genes, possibilitando a identificação da natureza transgênica do alimento. Estas informações não estarão mais presentes nos rótulos com a aprovação do PLC no 34/2015. Isso compromete o direito do consumidor, previsto pela Lei de Biossegurança brasileira $\mathrm{n}^{\circ} 11.105 / 2005$, fraudando exigência de informações claras e adequadas sobre a composição dos alimentos. Trata-se de ofensa ao preconizado na Estratégia Global para Promoção da Alimentação Saudável, Atividade Física e Saú$\mathrm{de}^{45}$ e garantido pelo Código de Defesa do Consumidor ${ }^{25}$.

Ademais, a identificação da presença de transgênicos apenas por meio de expressões como "(nome do produto) transgênico" ou "contém (nome do ingrediente) transgênico" no rótulo de alimentos com quantidade superior a 1\% de transgênicos é criticada em vista da-maioria da população brasileira não ter alta escolaridade (apenas $16,5 \%$ têm ensino superior completo $)^{46}$. Ademais, usualmente expostas em letras pequenas, em locais de difícil identificação no rótulo, estas informações não substituem adequadamente uma simbologia que já está incorporada no domínio público.

Grande parte dos produtos disponíveis no supermercado de referência contém algum ingrediente derivado de soja e milho, possivelmente 
transgênico, sem o informar no rótulo ${ }^{40}$. Portanto, a aprovação do PLC no 34/2015 vai contra o código de defesa do consumidor e na contramão das propostas atuais de rotulagem, que buscam cada vez mais auxiliar na escolha e na autonomia do consumidor. No Quadro 1 é possível observar as diferenças entre a legislação vigente e a proposta do PLC no 34/2015.

No Brasil, a Agência Nacional de Vigilância Sanitária (ANVISA) tem discutido e proposto o uso de símbolos (triângulos) para informar os consumidores sobre a composição nutricional de produtos alimentícios em relação ao conteúdo de açúcar, gordura e sal ${ }^{47}$, tornando os rótulos mais compreensíveis, com informações claras, simples e de fácil identificação. Embora estas mudanças se apliquem à rotulagem nutricional, podem também ser consideradas na rotulagem de transgênicos, visto que são complementares e visam atender a um mesmo objetivo, de informar o consumidor sobre a composição do alimento que está disposto a consumir, permitindo escolhas informadas. Contrariando este objetivo, o PLC no 34/2015 propõe a retirada de informação necessária ao atendimento de direito constitucionalmente assegurado.

Outro ponto a ser destacado é que, contrariando o que dispõe o artigo $3^{\circ}$ do Decreto $n^{\circ}$ 4.680/2003, o PLC no 34/2015 também prevê a exclusão da rotulagem dos alimentos e ingredientes produzidos a partir de animais alimentados com ração contendo ingredientes transgênicos. A justificativa para tal exclusão é a inexistência de regras no mercado internacional em relação a estes alimentos. Dinon et al. ${ }^{48}$ observou a presença da soja transgênica em seis de 59 amostras de carne processada e produtos à base de soja comerciados entre 2007-2008, no entanto, de acordo com a legislação brasileira, apenas uma amostra teria de ser rotulada. Além da grande quantidade de ingredientes transgênicos adicionados pela indústria alimentícia em carnes e preparações à base de carnes, os animais alimentados com ração produzida com milho e/ou soja transgênicas também podem constituir fonte de transgênicos para a alimentação humana. Esta informação deve ser disponibilizada ao consumidor, exigindo sua presença na rotulagem.

Quando a rotulagem é baseada no Princípio da Precaução, considera-se a origem da matéria-prima, independente da possibilidade de sua detecção no produto final. Isto incluiria todos os produtos altamente processados que não contêm DNA ou proteínas de transgênicos detectáveis, mas são derivados de culturas transgênicas, como o óleo de soja, milho ou algodão. Além disso, também se considera a presença de transgênicos no processo produtivo do alimento como, por exemplo, a utilização de levedura transgênica no processo de fermentação de um pão de trigo ${ }^{49,50}$.

A informação da presença de transgênicos no alimento ou sua presença no processo produtivo do alimento deveria aparecer sempre, independente do percentual de transgênicos no alimento. Isso porque alimentos derivados de soja e milho tendem a conter resíduos de agrotóxicos associados ao seu cultivo, causando riscos à saúde humana pelos efeitos já conhecidos destas substâncias.

A legislação brasileira permite a ausência de rotulagem naqueles alimentos com menos de $1 \%$ de transgênicos identificáveis, ainda que tenham sido elaborados a partir de grãos geneticamente modificados. Estudos têm revelado a presença de ingredientes transgênicos em limite superior a $1 \%$ sem explicitação no rótulo. Trata-se de claro descumprimento da legislação de rotulagem por parte da indústria alimentícia ${ }^{27,29,40,48}$.

Greiner e Konistzny ${ }^{27}$ verificaram a presença de diferentes produtos alimentícios constituídos de ingredientes derivados de soja e/ou milho transgênicos comercializados em supermercados no Brasil. A presença de soja transgênica em produtos contendo soja teve um aumento de $13 \%$ em 2000 para $78 \%$ em 2005, enquanto que independente do ano, cerca de $10 \%$ do milho presente em produtos alimentícios era transgênico. Em outro estudo $^{29}$, dos 240 alimentos contendo soja, 68 $(28,3 \%)$ continham soja transgênica, enquanto que em alimentos contendo milho, não foi encontrado milho transgênico. $O$ conteúdo de transgênicos variou de 0,05 a $1 \%$ em $43(63,2 \%)$ amostras e foi superior a $1 \%$ em $25(36,8 \%)$ amostras, porém nenhum destes produtos declarava a presença de transgênicos no rótulo, estando em desconformidade com a legislação de rotulagem.

Ressalta-se, também, a inexistência de estudos que estabeleçam um nível (percentual) de segurança para o consumo destes alimentos. Sendo assim, mesmo se um produto contiver níveis inferiores a $1 \%$ de transgênicos na sua composição, seu consumo terá impacto distinto sobre diferentes perfis de consumidores, de modo que é relevante o fato deste limite ter caráter operacional, não se baseando em análises de risco que contemplem famílias com histórico de insuficiência renal, de baixa imunidade, de alta propensão hereditária a alguns tipos de câncer e outras patologias.

Segundo a Recomendação no 009/2015 do Conselho Nacional de Segurança Alimentar e 
Quadro 1. Diferenças entre os Decretos nº 3.871/2001, $n^{\circ} 4.680 / 2003$, a Lei de Biossegurança ${ }^{\circ} 11.105 / 2005$, o Projeto de Lei ${ }^{\circ}$ $4.148 / 2008$ e o Projeto de Lei da Câmara no $34 / 2015$.

\begin{tabular}{|c|c|c|c|c|c|}
\hline \multirow[b]{2}{*}{ Característica } & \multicolumn{5}{|c|}{ Decretos/Projeto de Lei } \\
\hline & $\begin{array}{l}\text { Decreto } n^{\circ} \\
3.871 / 2001 \\
\text { Revogado }\end{array}$ & $\begin{array}{c}\text { Decreto } n^{\circ} 4.680 / 2003 \\
\text { Em vigor }\end{array}$ & \begin{tabular}{|c} 
Lei de \\
Biossegurança $\mathrm{n}^{\mathrm{o}}$ \\
$11.105 / 2005$ \\
Em vigor
\end{tabular} & $\begin{array}{c}\text { Projeto de Lei no } \\
4.148 / 2008 \\
\text { Em tramitação }\end{array}$ & $\begin{array}{c}\text { Projeto de Lei } n^{\circ} \\
34 / 2015 \\
\text { Em tramitação }\end{array}$ \\
\hline $\begin{array}{l}\text { Âmbito de } \\
\text { aplicação }\end{array}$ & $\begin{array}{l}\text { Alimentos } \\
\text { embalados, } \\
\text { destinados } \\
\text { ao consumo } \\
\text { humano }\end{array}$ & $\begin{array}{l}\text { Alimentos embalados, } \\
\text { vendidos a granel ou in } \\
\text { natura }\end{array}$ & $\begin{array}{l}\text { Alimentos e } \\
\text { ingredientes } \\
\text { alimentares } \\
\text { destinados ao } \\
\text { consumo humano } \\
\text { ou animal }\end{array}$ & $\begin{array}{l}\text { Alimentos } \\
\text { embalados, } \\
\text { vendidos a granel } \\
\text { ou in natura }\end{array}$ & $\begin{array}{l}\text { Alimentos } \\
\text { embalados, } \\
\text { vendidos a granel } \\
\text { ou in natura }\end{array}$ \\
\hline $\begin{array}{l}\text { Limite de } \\
\text { tolerância }\end{array}$ & $\begin{array}{l}4 \% \text { (estabelecido } \\
\text { para cada um } \\
\text { dos ingredientes } \\
\text { isoladamente) }\end{array}$ & $\begin{array}{l}1 \% \text { em relação ao peso do } \\
\text { produto ou ingrediente }\end{array}$ & $0 \%$ & $\begin{array}{l}1 \% \text { em relação ao } \\
\text { peso do produto }\end{array}$ & $\begin{array}{l}1 \% \text { em relação ao } \\
\text { peso do produto }\end{array}$ \\
\hline Expressão & $\begin{array}{l}\text { - (tipo do } \\
\text { produto) } \\
\text { geneticamente } \\
\text { modificado } \\
\text { - contém (tipo } \\
\text { de ingrediente) } \\
\text { geneticamente } \\
\text { modificado } \\
\end{array}$ & $\begin{array}{l}\text { - (nome do produto) } \\
\text { transgênico } \\
\text { - contém (nome do } \\
\text { ingrediente ou ingredientes) } \\
\text { transgênico(s) } \\
\text { - produto produzido } \\
\text { a partir de (nome do } \\
\text { produto) transgênico }\end{array}$ & Não cita & $\begin{array}{l}\text { - (nome do } \\
\text { produto) } \\
\text { transgênico } \\
\text { - contém (nome } \\
\text { do ingrediente) } \\
\text { transgênico }\end{array}$ & $\begin{array}{l}\text { - (nome do } \\
\text { produto) } \\
\text { transgênico } \\
\text { - contém (nome } \\
\text { do ingrediente) } \\
\text { transgênico }\end{array}$ \\
\hline $\begin{array}{l}\text { Presença da } \\
\text { espécie doadora } \\
\text { do gene }\end{array}$ & Não cita & $\begin{array}{l}\text { Deve conter essa informação } \\
\text { no local reservado para } \\
\text { a identificação dos } \\
\text { ingredientes }\end{array}$ & Não cita & $\begin{array}{l}\text { Não inclui essa } \\
\text { informação }\end{array}$ & $\begin{array}{l}\text { Não inclui essa } \\
\text { informação }\end{array}$ \\
\hline $\begin{array}{l}\text { Rotulagem de } \\
\text { alimentos GM } \\
\text { destinados } \\
\text { ao consumo } \\
\text { animal }\end{array}$ & Não cita & $\begin{array}{l}\text { Alimentos e ingredientes } \\
\text { produzidos a partir de } \\
\text { animais alimentados com } \\
\text { ração contendo ingredientes } \\
\text { transgênicos deverão ser } \\
\text { seguinte expressão: “(nome } \\
\text { do animal) alimentado com } \\
\text { ração contendo ingrediente } \\
\text { transgênico" ou “(nome do } \\
\text { ingrediente) produzido a } \\
\text { partir de animal alimentado } \\
\text { com ração contendo } \\
\text { ingrediente transgênico" }\end{array}$ & Não cita & Não cita & Se aplica \\
\hline $\begin{array}{l}\text { Rotulagem } \\
\text { facultativa de } \\
\text { alimentos não } \\
\text { GM }\end{array}$ & Não cita & $\begin{array}{l}\text { Alimentos que não } \\
\text { contenham OGM poderão } \\
\text { ser rotulados como “(nome } \\
\text { do produto ou ingrediente) } \\
\text { livre de transgênicos”, } \\
\text { desde que tenham similares } \\
\text { transgênicos no mercado }\end{array}$ & Não cita & $\begin{array}{l}\text { Alimentos que } \\
\text { não contenham } \\
\text { OGM poderão } \\
\text { ser rotulados } \\
\text { como "(nome } \\
\text { do produto ou } \\
\text { ingrediente) livre } \\
\text { de transgênicos", } \\
\text { desde que } \\
\text { tenham similares } \\
\text { transgênicos }\end{array}$ & Não cita \\
\hline $\begin{array}{l}\text { Presença do } \\
\text { símbolo }\end{array}$ & Não cita & Se aplica & Não & Não & Não \\
\hline
\end{tabular}

Fonte: Elaborado pelos autores. 
Nutricional (CONSEA), a rotulagem de transgênicos é uma medida de saúde pública relevante para permitir o monitoramento dos produtos, pós introdução no mercado, bem como para realizar pesquisas sobre os impactos ao ambiente e saúde ${ }^{51}$. Contudo, na lista nacional de doenças e agravos de notificação compulsória do Ministério da Saúde ${ }^{52}$ não há previsão de registro para doenças causadas pelo consumo de alimentos transgênicos, ou mesmo para sua identificação no rol de informações coletadas, o que na prática inviabiliza qualquer tipo de associação e acompanhamento.

Para garantia do cumprimento da atual legislação de rotulagem, a fiscalização deve ser partilhada entre os diversos órgãos competentes, em conformidade com suas atribuições legais. De acordo com a Instrução Normativa n ${ }^{\circ} 1 / 2004$, no âmbito federal, compete ao Ministério da Agricultura, Pecuária e Abastecimento (MAPA) a fiscalização da documentação fiscal no campo. Compete à ANVISA, do Ministério da Saúde, o acompanhamento da indústria alimentícia, restando ao Ministério da Justiça a fiscalização da oferta dos produtos aos consumidores, sendo também competentes os órgãos estaduais e municipais $^{53}$. Mas em relação a fiscalização e a realização de análises específicas prevista no PLC no 34/2015, não fica clara de quem é a responsabilidade para comprovar/atestar a presença ou ausência de material transgênico.

\section{Considerações finais}

As evidências sugerem que a rotulagem obrigatória aplicada a todos os produtos, baseada no processo de produção e sem limite mínimo de detecção é a única forma de garantir informação suficiente e escolhas adequadas para aqueles que não querem consumir transgênicos. Assim, o atual sistema de rotulagem de transgênicos não garante que os alimentos consumidos por aqueles que rejeitam ou entendam prejuízo em seu consumo de transgênicos, possam fazê-lo de maneira segura. Os produtos não rotulados como transgênicos e, mesmo aqueles rotulados como livres de transgênicos, não devem ser interpretados no quadro atual, como totalmente livres de transgênicos. Além disso, não foram encontra- das informações sobre fiscalização em relação ao cumprimento do percentual limite de ingredientes transgênicos nos alimentos. Assim, salvo melhor juízo, pode-se supor que a indústria alimentícia é estimulada a omitir essa informação, não rotulando inclusive alimentos que possam conter mais de $1 \%$ de transgênicos.

O PLC no 34/2015, se aprovado, pode comprometer ainda mais esta situação, fragilizando a rotulagem em vigor, abrindo brechas na legislação, dificultando a identificação de transgênicos. O símbolo $\mathrm{T}$ facilita a identificação da natureza transgênica do alimento e vem ao encontro das discussões e da proposta da ANVISA sobre o uso de símbolos (triângulos) para tornar os rótulos mais compreensíveis pelo consumidor. A retirada do símbolo, bem como as outras mudanças propostas pelo projeto, não é recomendada e caracteriza um retrocesso na regulamentação já aprovada e vigente no Brasil. Ao invés disso, devem ser envidados esforços e ações governamentais voltadas para a divulgação das informações presentes na rotulagem de alimentos, permitindo sua melhor compreensão pela população, especialmente aquela com menor escolaridade.

Por fim, embora não exista uma harmonização da legislação de rotulagem de alimentos transgênicos entre os países do Mercosul, a comercialização de alimentos transgênicos sem a devida identificação se caracteriza como um desrespeito aos direitos individuais e coletivos previstos na Constituição Federal, no Código de Defesa do Consumidor e em acordos internacionais assinados pelo Brasil.

Espera-se que este ensaio contribua para qualificar ações de fiscalização e revisões positivas na legislação brasileira de rotulagem de transgênicos, ampliando a confiabilidade dos rótulos e garantindo possibilidade aos cidadãos de tomar decisões informadas com base na composição dos alimentos, exercendo pressões de consumidores conscientes que fazem das decisões de consumo, atividades políticas responsáveis.

Por fim, a adoção do Princípio da Precaução exige que na constatação de incertezas, os produtos sejam rotulados, tanto com base na documentação fiscal que acompanha os produtos, como com base em testes de detecção de DNA ou de proteínas. 


\section{Colaboradores}

RDM Cortese contribuiu com a concepção, elaboração e revisão do artigo. RK Fabri, SS Martinelli, L Melgarejo e RO Nodari contribuíram com a revisão crítica do artigo. SB Cavalli contribuiu com a concepção e revisão do artigo.

\section{Agradecimentos}

À Coordenação de Aperfeiçoamento de Pessoal de Nível Superior (CAPES) pelo apoio financeiro na forma de bolsas de estudos para RDM Cortese, RK Fabri e SS Martinelli. Esse trabalho foi conduzido como parte de um estudo mais amplo sobre a compreensão e uso da rotulagem de alimentos no Brasil, financiado pelo Conselho Nacional de Desenvolvimento Científico e Tecnológico (CNPq) do Ministério da Ciência e Tecnologia do Brasil e pela Agência Nacional de Vigilância Sanitária (ANVISA).

\section{Referências}

1. James C. Global Status of Commercialized Biotech/GM Crops: 2018. Ithaca: International Service for the Acquisition of Agri-biotech Applications/ISAAA Brief $n^{\circ} .54 ; 2018$.

2. Organization for Economic Co-operation and Development \& Food and Agriculture Organization of the United Nations (OECD-FAO). Agricultural Outlook 2015. Paris: OECD-FAO; 2015.

3. Price B, Cotter J. The GM Contamination Register: a review of recorded contamination incidents associated with genetically modified organisms (GMOs), 1997-2013. J Food Contamination 2014; 1(1):1-13.

4. Hilbeck A, Binimelis R, Defarge N, Steinbrecher R, Székács A, Wickson F, Antoniou M, Bereano PL, Clark EA, Hansen M, Novotny E, Heinemann J, Meyer H, Shiva V, Wynne B. No scientific consensus on GMO safety. Environ Sci Eur 2015; 27:4.

5. Pusztai A. Genetically Modified Foods: Are They a Risk to Human/Animal Health? Action Biosci 2001; 1-10.

6. Nodari RO, Guerra MP. Transgenic plants and their products: effects, risks and food safety (Biosafety of transgenic plants). Rev Nutr 2003; 16(1):105-116.

7. Bawa AS, Anilakumar KR. Genetically modified foods: safety, risks and public concerns-a review. $J$ Food Sci Technol 2013; 50(6):1035-1046.

8. Andreassen M, Rocca E, Bøhn T, Wikmark O-G, van den Berg J, Løvik M, Traavik T, Nygaard UC. Humoral and cellular immune responses in mice after airway administration of Bacillus thuringiensis Cry1 Ab and MON810 crylAb-transgenic maize. Food Agr Immunol 2014; 26(4):521-537.

9. Carneiro FF, Augusto LGdS, Rigotto RM, Friedrich K, Búrigo AC. Dossiê ABRASCO: Um alerta sobre os impactos dos agrotóxicos na saúde. Rio de Janeiro, São Paulo: MS, Fiocruz, EPSJV, Expressão Popular; 2015.

10. Almeida VES, Friedrich K, Tygel AF, Melgarejo L, Carneiro FF. Use of genetically modified crops and pesticides in Brazil: growing hazards. Cien Saude Colet 2017; 22(10):3333-3339.

11. Bombardi LM. Geografia do uso de agrotóxicos no Brasil e conexões com a União Europeia. São Paulo: FFLC - USP; 2017.

12. Shao Q, Chin KV. Survey of American food trends and the growing obesity epidemic. Nutr Res Pract 2011; 5(3):253-259.

13. Weintraub K. The prevalence puzzle: Autism counts. Nature 2011; 479(7371):22-24.

14. Mostafalou S, Abdollahi M. Pesticides and human chronic diseases: evidences, mechanisms, and perspectives. Toxicol Appl Pharmacol 2013; 268(2):157177.

15. Samsel A, Seneff S. Glyphosate, pathways to modern diseases II: Celiac sprue and gluten intolerance. Interdiscip Toxicol 2013; 6(4):159-184.

16. Samsel A, Seneff S. Glyphosate's Suppression of Cytochrome P450 Enzymes and Amino Acid Biosynthesis by the Gut Microbiome: Pathways to Modern Diseases. Entropy 2013; 15:1416-1463.

17. Swanson NL, Leu A, Abrahamson J, Wallet B. Genetically engineered crops, glyphosate and the deterioration of health in the United States of America. J Organic Syst 2014; 9(2):6-37. 
18. Thongprakaisang S, Thiantanawat A, Rangkadilok N, Suriyo T, Satayavivad J. Glyphosate induces human breast cancer cells growth via estrogen receptors. Food Chem Toxicol 2013; 59(0):129-136.

19. von Ehrenstein OS, Ling C, Cui X, Cockburn M, Park AS, Yu F, Wu J, Ritz B. Prenatal and infant exposure to ambient pesticides and autism spectrum disorder in children: population based case-control study. BMJ 2019; 364:1962.

20. Kim KH, Kabir E, Jahan SA. Exposure to pesticides and the associated human health effects. Sci Total Environ 2017; 575:525-535.

21. Koifman S, Koifman RJ, Meyer A. Human reproductive system disturbances and pesticide exposure in Brazil. Cad Saude Publica 2002; 18:435-445.

22. United Nations (UN). Convention on Biological Diversity. Rio de Janeiro: UN; 1992.

23. Secretariat of the Convention on Biological Diversity. Cartagena Protocol on Biosafety to the Convention on Biological Diversity. Montreal: Secretariat of the Convention on Biological Diversity; 2000.

24. Myhr AI, Traavik T. Genetically modified (GM) drops: precautionary science and conflicts of interests. J Agric Environ Ethics 2003; 16:227-247.

25. Brasil. Lei no 8.078 , de 11 de setembro de 1990. Dispõe sobre a proteção do consumidor e dá outras providências. Diário Oficial da União 1990; 11 set.

26. Bertolini M, Bevilacqua M, Massini R. FMECA approach to product traceability in the food industry. Food Control 2006; 17(2):137-145.

27. Greiner R, Konietzny U. Presence of genetically modified maize and soy in food products sold commercially in Brazil from 2000 to 2005. Food Control 2008; 19(5):499-505.

28. Branquinho MR, Gomes DMV, Ferreira RTB, Lawson-Ferreira R, Cardarelli-Leite P. Detection of genetically modified maize events in Brazilian maize-derived food products. Food Sci Technol 2013; 33:399-403.

29. Branquinho MR, Ferreira RTB, Cardarelli-Leite P. Survey of compliance with labeling legislation in food containing GMOs in Brazil. J Food Compos Anal 2010; 23(3):220-225

30. Ferreira RTB, Branquinho MR, Cardarelli-Leite P. Genetically modified soybean in food containing wheat flour and wheat flour-based preparations. Detection and fitness to labeling legislation. Braz J Food Technol 2009; 12:241-248.

31. World Health Organization (WHO). Modern food biotechnology, human health and development: an evidence-based study. Geneva: WHO; 2005.

32. Burlingame B, Pineiro M. The essential balance: Risks and benefits in food safety and quality. J Food Compos Anal 2007; 20(8):739.

33. Gruère GP, Rao SR. A review of international labeling policies of genetically modified food to evaluate India's proposed rule. Ag Bio Forum 2007; 10(1):51-64.

34. Canadian Biotechnology Advisory Committee. Improving the Regulation of Genetically Modified Foods and Other Novel Foods in Canada: Report to the Government of Canada Biotechnology Ministerial Coordinating Committee. Canada: Canadian Biotechnology Advisory Committee; 2001.
35. Brasil. Decreto Federal no 4.680 , de 24 de abril de 2003. Regulamenta o direito à informação, assegurado pela Lei no. 8.078, de 11 de setembro de 1990, quanto aos alimentos e ingredientes alimentares destinados ao consumo humano ou animal que contenham ou sejam produzidos a partir de organismos geneticamente modificados. Diário Oficial da União 2003; 24 abr.

36. Brasil. Lei $\mathrm{n}^{\circ} 11.105$, de 24 de março de 2005. Regulamenta os incisos II, IV e V do $\$ 1{ }^{\circ}$ do art. 225 da Constituição Federal, estabelece normas de segurança e mecanismos de fiscalização de atividades que envolvam organismos geneticamente modificados. Diário Oficial da União 2005; 24 mar.

37. Brasil. Ministério da Justiça. Portaria no 2.658, de 22 de dezembro de 2003. Define o símbolo de que trata o art. $2^{\circ}, \$ 1^{\circ}$, do Decreto ${ }^{\circ} 4.680$, de 24 de abril de 2003, na forma do anexo à presente portaria. Diário Oficial da União 2003; 22 dez.

38. Brasil. Decreto $\mathrm{n}^{\circ}$ 3.871, de 18 de julho de 2001 . Disciplina a rotulagem de alimentos embalados que contenham ou sejam produzidos com organismo geneticamente modificados, e dá outras providências. Revogado pelo Decreto no 4.680 , de 24 de abril de 2003. Diário Oficial da União 2001; 18 jul.

39. Brasil. Projeto de Lei da Câmara $\mathrm{n}^{\circ}$ 34, de 2015 (n 4.148/2008, na Casa de origem). 2015

40. Cortese RDM. Análise da rotulagem de alimentos elaborados a partir de organismos geneticamente modificados: A situação do Brasil [tese]. Florianópolis: Universidade Federal de Santa Catarina; 2018.

41. Cortese RDM, Martinelli SS, Fabri RK, Cavalli SB. Alimentação na atualidade: Reflexões sobre o consumo de alimentos geneticamente modificados. Agroecología 2017; 2(12):71-79.

42. Cortese RDM, Martinelli SS, Fabri RK, Proença RPC, Cavalli SB. A label survey to identify ingredients potentially containing GM organisms to estimate intake exposure in Brazil. Public Health Nutr 2018; 21(14):2698-2713.

43. Supremo Tribunal Federal (STF). Medida Cautelar na Reclamação 14.873 Distrito Federal. Brasília: Supremo Tribunal Federal; 2012.

44. Hakim MP, Zanetta LDA, de Oliveira JM, da Cunha DT. The mandatory labeling of genetically modified foods in Brazil: Consumer's knowledge, trust, and risk perception. Food Res Int 2020; 132:109053.

45. World Health Organization (WHO). Global Strategy on Diet, Physical Activity and Health. Geneva: WHO; 2004.

46. Instituto Brasileiro de Geografia e Estatística (IBGE). Pesquisa Nacional por Amostras de Domicílios Contínua 2016-2018. Rio de Janeiro: IBGE; 2018.

47. Khandpur N, Mais LA, Sato PM, Martins APB, Spinillo CG, Rojas CFU, Garcia MT, Jaime, PC. Choosing a front-of-package warning label for Brazil: A randomized, controlled comparison of three different label designs. Food Res Int 2019; 121:854-861.

48. Dinon AZ, Treml D, de Mello CS, Arisi ACM. Monitoring of GMO in Brazilian processed meat and soy-based products from 2007 to 2008. J Food Compos Anal 2010; 23(3):226-229. 
49. Gruère GP. A preliminary comparison of the retail level effects of genetically modified food labelling policies in Canada and France. Food Policy 2006; 31:14.

50. Food and Agriculture Organization of the United Nations (FAO). Biosafety Resource Book. Rome: FAO; 2011.

51. Conselho Nacional de Segurança Alimentar e Nutricional (CONSEA). Recomendação do CONSEA n ${ }^{\circ}$ 009/2015. Brasília: CONSEA; 2015.

52. Brasil. Ministério da Saúde (MS). Portaria no 1.271, de 6 de junho de 2014. Define a Lista Nacional de Notificação Compulsória de doenças, agravos e eventos de saúde pública nos serviços de saúde públicos e privados em todo o território nacional, nos termos do anexo, e dá outras providências. Diário Oficial da União 2014; 6 jun.

53. Brasil. Ministério da Saúde (MS). Instrução Normativa ${ }^{\circ} 1$ de 01 de abril de 2004. Regulamento técnico sobre rotulagem de alimentos e ingredientes alimentares que contenham ou sejam produzidos a partir de organismos geneticamente modificados. Diário Oficial da União 2004; 01 abr.

Artigo apresentado em 08/01/2020

Aprovado em 27/10/2020

Versão final apresentada em 29/10/2020

Editores-chefes: Romeu Gomes, Antônio Augusto Moura da Silva 